|| ISSN(online): 2589-8698 || ISSN(print): 2589-868X ||

International Journal of Medical and Biomedical Studies

Available Online at www.ijmbs.info

NLM (National Library of Medicine ID: 101738825)

Index Copernicus Value 2019: 79.34

Original Research Article

Volume 5, Issue 7; July: 2021; Page No. 42-44

\title{
ROLE OF HYPERBILIRUBINEMIA IN PREDICTON OF GANGRENOUS/PERFORATED APPENDICITIS
}

\section{Dr. Irfan Hussain Khan ${ }^{1}$, Dr. Arun Bhargava ${ }^{2}$}

${ }^{1}$ Assistant Professor, Department of General Surgery, National Institute of Medical Sciences \& Research, NIMS, University, Jaipur

${ }^{2}$ Assistant Professor, Department of General Surgery, National Institute of Medical Sciences \& Research, NIMS, University, Jaipur

Article Info: Received 06 May 2021; Accepted 02 July 2021

DOI: https://doi.org/10.32553/ijmbs.v5i7.2011

Corresponding author: Dr Arun Bhargava

Conflict of interest: No conflict of interest.

\begin{abstract}
Introduction: The aim of this study was to determine the role of hyperbilirubinemia as a new diagnostic tool for predictor of gangrenous / perforated appendicitis.

Methods: Hospital based prospective study was conducted on 100 patients with perforated/gangrenous appendix

Results: In acute appendicitis case out of 84 cases 26 cases bilirubin level was more than $1 \mathrm{mg} / \mathrm{dl}$, in gangrenous appendicitis out of 3 cases all cases bilirubin level was more than $1 \mathrm{mg} / \mathrm{dl}$ and in perforated appendicitis out of 13 cases 12 cases bilirubin level was more than $1 \mathrm{mg} / \mathrm{dl}$

Conclusion: It is concluded from present study that elevated total serum bilirubin without elevation of liver enzymes is a good indicator of appendicular perforation.
\end{abstract}

Keywords: Perforation, Appendicitis, Bilirubin

\section{Introduction}

Serum Bilirubin level elevation will help in the accuracy of clinical diagnosis of acute appendicitis and more importantly help in foreseeing and preventing impending complications of acute appendicitis. Whereas nonperforated acute appendicitis can be cured by an appendectomy without a long recovery period, perforated appendicitis or suppurative appendicitis can cause various complications that can result in life-threatening conditions. Hyperbilirubinemia is the result of imbalance between synthesis and excretion of bilirubin by the liver. Portal blood carries nutrients and other substances absorbed from gut including bacteria and its product (toxins). It is commonly cleared by detoxification and immunological action of the reticuloendothelial system of the liver that acts as first-line defense in clearing toxic substances, bacteria and its products. But when bacterial load overwhelms the Kupffer cell function, it may cause dysfunction or damage to hepatocytes (liver parenchyma). It reflects a rise in serum bilirubin (SB) alone or in combination with liver enzymes depending upon the type, severity and site of the lesion. ${ }^{1-3}$ So we conducted study on role of hyperbilirubinemia as a new diagnostic tool for predictor of gangrenous/ perforated appendicitis.

\section{Materials and Methods}

1. Study design: Cross sectional Hospital based study

2. Study place: Department of General Surgery
3. Study population: All patients with perforated/gangrenous appendix admitted in ward of department of surgery

4. Sampling technique: Consecutive sampling

5. Sample size: all eligible patients admitted in surgery ward were included in study

6. Inclusion criteria: All patients with right iliac fossa pain clinically suggestive of appendicitis or appendicular perforation.

7. Exclusion criteria: All patients documented to have a past history of Jaundice or liver disease, positive HbsAg, cholelithiasis, cancer of hepatobiliary system.

\section{Method:}

$>$ Clinical signs of acute appendicitis determined by the surgeons and the duration of the symptoms were documented on admission.

An informed consent were obtained from all registered cases.

$>$ In all patients with pain in right iliac fossa the provisional diagnosis of acute appendicitis will be made on the basis of history, clinical signs and relevant clinical data.

Routine laboratory investigations were carried out like Haemoglobin, TLC count, Neutrophil count, Serum Bilirubin, Liver enzymes, which include SGPT (Alanine transaminase), SGOT (Aspartate transaminase), ALP 
(Alkaline phosphatase), Urine routine microscopy, Chest Xray PA, X-Ray abdomen erect, Ultrasonography abdomen and pelvis, Urine pregnancy test in suspected pregnancy.

Serum Bilirubin level measurement was done in all patients by fully automatic analyzer machine.
Statistical Analysis: Statistical analysis were performed using ANNOVA and $\mathrm{P}$ value $<0.05$ will be checked for statistical significance of the obtained data.

\section{Observations}

Table 1: liver function tests

\begin{tabular}{|l|l|l|l|l|}
\hline Parameters & $\begin{array}{l}\text { Uncomplicated } \\
(\mathbf{n = 8 5})\end{array}$ & $\begin{array}{l}\text { Perforated } \\
\text { appendicitis }\end{array}$ & $\begin{array}{l}\text { Gangrenous } \\
\text { appendicitis }\end{array}$ & p-value \\
\hline Total bilirubin(mg/dl) & $0.92 \pm 0.31$ & $2.13 \pm 0.82$ & $2.39 \pm 1.25$ & $\mathbf{0 . 0 0 1}$ \\
\hline Direct bilirubin(mg/dl) & $0.56 \pm 0.29$ & $1.69 \pm 0.72$ & $2.01 \pm 1.36$ & $\mathbf{0 . 0 0 1}$ \\
\hline Indirect bilirubin(mg/dl) & $0.31 \pm 0.16$ & $0.49 \pm 0.16$ & $0.43 \pm 0.11$ & $\mathbf{0 . 0 0 1}$ \\
\hline SGOT (IU/L) & $32.13 \pm 9.10$ & $57.32 \pm 17.11$ & $50.23 \pm 25.16$ & $\mathbf{0 . 0 0 1}$ \\
\hline SGPT (IU/L) & $29.25 \pm 7.06$ & $50.06 \pm 12.31$ & $62.36 \pm 23.16$ & $\mathbf{0 . 0 0 1}$ \\
\hline ALP (IU/L) & $64.19 \pm 18.21$ & $142.36 \pm 42.12$ & $129.36 \pm 41.23$ & $\mathbf{0 . 0 0 1}$ \\
\hline
\end{tabular}

Total bilirubin $(\mathrm{mg} / \mathrm{dl})$ in uncomplicated cases was $0.92 \pm 0.31 \mathrm{mg} / \mathrm{dl}$, in perforated appendicitis was $2.13 \pm 0.82 \mathrm{mg} / \mathrm{dl} \mathrm{and}$ in perforated appendicitis was $2.39 \pm 1.25 \mathrm{mg} / \mathrm{dl}$.

Table 2: Association between histopathological diagnosis and total bilirubin

\begin{tabular}{|l|l|l|l|}
\hline \multirow{2}{*}{ HPE diagnosis } & \multicolumn{2}{|c|}{ Total bilirubin } & Total \\
\cline { 2 - 4 } & $<\mathbf{1 m g} / \mathbf{d l}$ & $>\mathbf{1 m g} / \mathbf{d l}$ & \\
\hline Acute appendicitis & 58 & 26 & 84 \\
\hline Gangrenous appendicitis & 0 & 3 & 3 \\
\hline Perforated appendicitis & 1 & 12 & 13 \\
\hline
\end{tabular}

p-value $=0.001$

In acute appendicitis case out of 84 cases 26 cases bilirubin level was more than $1 \mathrm{mg} / \mathrm{dl}$, in gangrenous appendicitis out of 3 cases all cases bilirubin level was more than $1 \mathrm{mg} / \mathrm{dl}$ and in perforated appendicitis out of 13 cases 12 cases bilirubin level was more than $1 \mathrm{mg} / \mathrm{dl}$.

\section{Discussions}

Acute appendicitis remains the most common acute surgical condition of the abdomen, it is also the most commonly misdiagnosed condition. Appendectomy is the most commonly performed emergency procedure for acute appendicitis in the world. The life time risk of developing acute appendicitis is $8 \%$ for people in western countries. ${ }^{4}$

Majority of appendicitis is believed to be caused by appendicular lumen obstruction. These luminal obstructions is usually caused by faecolith. Less common causes are lymphoid tissue hypertrophy, intestinal parasites, and tumors. Normally appendix contains bacterial flora similar to that present in normal large intestine. Escherichia coli and Bacteroids fragilis are the most common organism observed in normal appendix, acute appendicitis, perforated appendicitis and gangrenous appendicitis. However a broad variety of both anaerobic and facultative bacteria may be present. $^{5}$

Acute appendicitis is diagnosed essentially by clinical examination. It is often difficult to reach a proper diagnosis as classical signs and symptoms suggesting acute appendicitis may not be present in all. Different presenting symptoms and clinical signs always mimic the diagnosis of acute appendicitis, especially in women. The decision to operate based purely on clinical suspicion alone can lead to removal of normal appendix in $15-50 \%$ of cases. Precise diagnosis can be assisted by additional tests and expectant management or both. The above delay in diagnosis may lead to appendiceal perforation or gangrene leading to increased morbidity. Safe alternative considered is to do appendectomy as soon as condition is suspected, this strategy leads to unnecessary appendectomy. There is still ongoing debate regarding optimal management of acute appendicitis with several studies proposing that conservative, non- operative management may be feasible. ${ }^{6}$

Conclusion

It is concluded from present study that elevated total serum bilirubin without elevation of liver enzymes is a good indicator of appendicular perforation. Total serum bilirubin appears to be a new promising laboratory marker for diagnosing appendicular perforation. The patients with clinical signs and symptoms of appendicitis and with hyperbilirubinemia should be identified as having a higher probability of appendicular perforation suggesting, total serum bilirubin levels have a predictive potential for the diagnosis of appendicular perforation.

\section{References}

1. Estrada JJ, Petrosyan M, Krumenacker J Jr, Huang S, Moh P. Hyperbilirubinemia in Appendicitis: A New Predicator of Perforation. Journal of Gastrointestinal Surgery 2007; 11: 714-5. 
2. Khan S. Evaluation of hyperbilirubinemia in acute inflammation of appendix: A prospective study of 45 cases. KUMJ 2006; 4(3) 15: 281-9

3. Muzna Iftikhar. Hyperbilirubinemia as an indicator of complicated appendicitis . International Journal of Surgery and Medicine (2019) 5(2):58-65

4. Flum DR, Morris A, Koepsell T, Dellinger EP. Has misdiagnosis of appendicitis decreased over time? a populationbased analysis. Jama. 2001;286 (14):
5. 1748-53.

6. Bickell NA, Aufses AH, Rojas M, Bodian C. How time affects the risk of rupture in appendicitis. $\mathrm{J}$ Am Coll Surg. 2006;202(3):401-6.

7. Fike FB, Mortellaro VE, Juang D, Sharp SW, Ostlie DJ, St Peter SD. The impact of postoperative abscess formation in perforated appendicitis. J Surg Res. 2011; 170(1):24-6. 